\title{
VOCES DE CREACIÓN METAFÓRICA SOBRE EL MAÍZ Y EL TRIGO EN EL ATLAS LINGÜÍSTICO Y ETNOGRÁFICO DE ARAGÓN, NAVARRA Y RIOJA
}

\author{
María Trinidad Fuster Berenguer
}

\begin{abstract}
According to the Dictionary of the Academy, metaphor is defined as 'a trope that results from the transfer of the exact meaning of a word to a figurative meaning through a tacit comparison'. One meaning can produce new senses that sometimes do not emerge from the initial idea but rather from a metaphor: for example, pelo (hair) for 'corn silk' (ALEANR, I, 107), bigote (moustache) for 'corn silk' (ALEANR, I, 107), corazón (heart) for 'pit, stone' (ALEANR, I, 111), etc. In this paper we point out some terms that have acquired meaning through metaphor. All of these terms can be found in the Atlas Lingüistico y Etnográfico de Aragón, Navarra y Rioja (The Linguistic and Ethnographic Atlas of Aragon, Navarra, and Rioja) and refer to corn or wheat.
\end{abstract}

Según el Diccionario de la Academia' una metáfora es un 'tropo que consiste en trasladar el sentido recto de las voces a otro figurado, en virtud de una comparación tácita'. Para Fernando Lázaro Carreter una metáfora es un 'tropo mediante el cual se presentan como idénticos dos términos distintos'?2.

La lengua participa de todos los hechos que caracterizan la vida puesto que son los hablantes quienes hacen la lengua. Las palabras no tienen un significado fijo sino que éste va evolucionando según las necesidades de los hablantes. De una acepción pueden salir nuevos significados que a veces no proceden de la idea inicial sino que han surgido a través de una metáfora.

I Real Academia Española, Diccionario de la lengua española, Espasa-Calpe, Madrid, $1992,21^{a}$ edic. En adelante citaremos como DRAE. s.v. metáfora.

2 F. Lázaro Carreter, Diccionario de términos filológicos, Gredos, Madrid, 1974, $3^{\text {a }}$ edic., 
Entre las voces que el Atlas Lingüístico y Etnográfico de Aragón, Navarra y Rioja ${ }^{3}$ recoge para denominar al maíz y al trigo hemos encontrado algunos términos en los que se han producido metáforas. Dichas voces de creación metafórica son una manera de enriquecer el léxico creando nuevas palabras.

I. La 'barba de la mazorca' recibe las siguientes denominaciones metafóricas: pelo, cabellera, seda, bigote.

Pelo 'barba de la mazorca' (ALEANR, I, 107).

Es una voz general de Aragón, Navarra y la Rioja ${ }^{4}$.

Pelo es el 'filamento cilíndrico, sutil, de naturaleza córnea, que nace y crece entre los poros de la piel de casi todos los mamíferos y de algunos otros animales de distinta clase' (DRAE). Si bien en un primer momento pelo designaba solamente el del cuerpo del hombre y los animales ahora designa otras cosas dándose con ello una metáfora debida a las semejanzas entre el cabello animal y humano con la barba o pelos de la mazorca.

Cabellera 'barba de la mazorca' (ALEANR, I, 107). Aparece en algunos puntos de la frontera catalano-aragonesa'.

Cabellera es 'pelo de la mazorca', luego no es un pelo, sino un conjunto de pelos, siendo, pues, un sustantivo colectivo ya que engloba a un grupo. La barba de la mazorca es, también, una globalidad de pelos, esta vez, rojizos, produciéndose con ello una metáfora.

II. La 'mazorca' recibe la voz metafórica de cabeza.

Cabeza 'mazorca' (ALEANR, 1, 109). Se localiza en el oeste de Navarra'.

Cabeza es 'principio o parte extrema de una cosa' (DRAE). En este caso Ia cabeza sería el principio o parte extrema de la planta del maíz, esto es, donde están los granos rodeados por hojas. Se ha producido una metáfora debido a la

\footnotetext{
M. Alvar, con la colaboración de A. Llorente, T. Buesa y E. Alvar, Atlas Lingüístico y Emográfico de Aragón, Navarra y Rioja, Departamento de Geografía Lingüistica, Instituto Fernando el Católico de la Excma. Diputación de Zaragoza, CSIC, Zaragoza, 1979-1983, 12 tomos. En adelante citaremos como ALEANR.

4 (Cuando no indicamos nada se trata de pelo: Lo 100 (pelos), 101, 103, 300 (pelos), 301, 304 (pelo de maíz) 400, 40I, 600, 601, 603,604 (pelo de maíz), 605 (pelos); Na 102, 105 (y pelillo), 206, 300 (y pelo de maíz), 301 (id.), 302 (pelos), 305, 307, 308, 400 (pelo de maíz)), 402 (pelos), 403, 404, 500, 501 (pelo de maíz), 602 (pelo(s) de (la) piña); $Z$ 100, 200, 300 (pelo(s) de (la) pinocha), 301 (pelo(s) de (la) piña), 302, 303, 304 (pelo(s) de (la) pinocha), 305, 400, 401,402 (pelo(s) de (la) pinocha), 500, 501, 502 (pelos y pelo(s) de (la) piña), 503, 504 (pelos de vieja), 506 (pelos), 507, 600 (pelo(s) de (la) pinocha), 602 (pelo(s) de (la) piña), 603 (pelo de panolla), 604, 605 (pelo de panolla), 606 (pel de panolla), 607; Hu 100, 101 (pelo del panicero), 104 (pelos), 105, 106, 107 (y pelos), 110 (pelos), 111, 112,203 (pelos), 204 (id.). 206 (íd.), 207, 300 (pelos), 301 (pelo(s) de (la) panocha), 303, 304, 305, 400, 403 (pelos), 405, 406, 407, 600, 601; Te 100, 101 (pelillo), 102 (pel de panolla), 104 (pelo(s) de (la) piña), 201, 203, 204, 206, 300, 301 (pelo(s) de (la) piña), 304, 308, $400,401,402,403,404,405,406,500,501,503,504,600,601 ; C s 300,301,302 ; \mathrm{V} \mathrm{100,101;Cu}$ 200, 400; Vi 300, 600; Bu 400; Gu 200).
}

$5 \quad$ (Te 200 (cabello), 207; Hu 602, 408).

6 (Na 100, 103, 104 (cabeza de maíz), 105, 106, 202, 301, 302, 303,305, 306, 307, 401). 
similitud (en cuanto al lugar que ocupa) entre la mazorca y la cabeza (ésta siempre aparece en una parte alta: cabeza del cuerpo, de un clavo, etc.).

III. En 'flor del maíz' encontramos los siguientes términos metafóricos: escoba, cabeza.

Escoba 'flor del maíz' (ALEANR, $I, 106)^{7}$.

Escoba es 'manojo de palmitos, de algarabía, de cabezuela o de otras ramas flexibles, juntas y atadas a veces al extremo de un palo, que sirven para barrer y limpiar, etc.' (DRAE). Se ha producido una metáfora debido a la similitud existente entre la flor del maiz, que es una especie de escobilla, y escoba.

Cabeza 'flor del maíz' (ALEANR, I, 106). Se halla en puntos bastante dispersos ${ }^{8}$.

La cabeza es el 'principio o parte extrema de una cosa' (DRAE). Se ha producido una metáfora debido a la situación en la que se encuentra la flor del maíz.

IV. La 'farfolla' tiene la voz metafórica de capota.

Capota 'farfolla' ( $A L E A N R, \mathrm{I}, 108$ ). Se encuentra en algunas localidades de Logroño y en una de Huesca?.

El DRAE afirma que capota es 'capeta, capa corta'. Una capa cubre el cuerpo de una persona como la farfolla cubre la mazorca del maíz. De ahí que se halla producido una metáfora.

V. El 'carozo' recibe las denominaciones metafóricas de corazón y troncho.

Corazón 'carozo' (ALEANR, I, 111). Aparece en algunas poblaciones de Logroño, Navarra, Huesca, Zaragoza, Teruel y Castellón ${ }^{10}$.

Corazón es 'órgano central de la circulación de la sangre' (DRAE). El corazón del hombre está en el interior de su cuerpo como el carozo de la mazorca, por lo que se ha dado una metáfora.

Troncho 'carozo' (ALEANR, I, 111). Se encuentra en dos localidades de Logroño y Navarra" .

El DRAE afirma que troncho es el 'tallo de las hortalizas'. Se ha producido una metáfora ya que el carozo es similar al tallo de las hortalizas.

VI.'Desfarfollar' tiene las voces metafóricas de (d)escapotar y espalocar.

(D) escapotar 'desfarfollar' (ALEANR, I, 110). Aparece en algunas poblaciones de Logroño y en una localidad de Navarra ${ }^{12}$.

7 (Si no indicamos nada se trata de escoba: $\mathrm{Lo} 100 ; \mathrm{Na} 301$ (escobilla), 302; Z 302; Hu 600 (escobeta), 601 (id.); Na 301 (escobilla), 304 (íd.), 308 (íd.), 601 (íd.)).

8 (Cuando no indicamos nada se trata de cabeza: $\mathrm{Na} \mathrm{401;} \mathrm{Hu} \mathrm{107,} \mathrm{109,} \mathrm{400,} \mathrm{401,} 408$ (cabesa)).

9 (Lo 100, 101, 103, 300, 301, 305, 400, 401; Hu 301).

11) (Lo 102; Na 601, 602; Hu 101, 201, 205, 403; Z300, 301, 304, 400, 501, 504, 505, 600, 602; Te 305, 401, 403; C. 301).

11 (Lo 300, 400; $\mathrm{Na} 404,600)$.

12 (Cuando no indicamos nada se trata de escapotar, forma más utilizada: Lo 100, 101 (descapotar), 103 (id.), 300 (id.), 301, 304 (quitar la capota), 400, 401; Na 301 (escaporar)). 
Descapotar es 'quitar la capota' (DRAE). Capota como ya hemos explicado en líneas anteriores significa 'capeta, capa corta' (DRAE) produciéndose con ello una metáfora; con descapotar se ha dado una metáfora similar ya que si capota era 'farfolla' quitar la farfolla será pues descapotar.

Espalocar 'desfarfollar' (ALEANR, I, 110). Se sitúa en cuatro localidades de Huesca ${ }^{13}$.

De peluca se forma la voz despelucar 'quitar la peluca' y de ahí 'quitar las hojas del maíz' por asociación de imágenes.

VII. El 'trigo a punto de espigar' recibe el siguiente término metafórico: (en) zurrón.

(En) zurrón 'trigo a punto de espigar' (ALEANR, I, 48). Es una voz muy extendida que aparece en Logroño, Navarra, Teruel, Soria, Guadalajara y Burgos $^{14}$.

El Diccionario de Autoridades recoge varias acepciones. Es interesante señalar dos de ellas:

1. 'en algunos frutos aquella cáscara primera y más tierna, en que están encerrados, y como defendidos y guardados'.

2. 'en el trigo y semillas semejantes, la parte alta de la caña, en que se va formando y está encerrada la espiga antes de prorrumpir, y es como el capillo de las flores'.

Actualmente, en el DRAE encontramos que zurrón es la "cáscara primera y más tierna en que están encerrados y como defendidos y guardados algunos frutos para que lleguen a su perfecta sazón'. Este último sentido es muy parecido a uno de los que hemos destacado de Autoridades. El significado originario, y general, de zurrón es 'bolsa en general'. Por proceso metafórico habrá llegado a 'cáscara primera de algunos frutos' (Autoridades y DRAE) y desde aquí, por restricción semántica, se ha especializado como 'trigo a punto de espigar'.

VIII. La 'lleta' posee las siguientes voces metafóricas: flecha, punzón, puga, aguja.

Flecha 'lleta' (ALEANR, I, 49). Se encuentra en cinco localidades de Zaragoza, una de Teruel y otra de Huesca's.

13. (Hu 103 (espalocar), 105, 106 (espelocar), 203 (espellocar)).

14 (Cuando no indicamos nada se trata de (en) (el) zurrón que es la forma mayoritaria: $L o$ 100, 101 (pa(ra) deszurronar), 102, 103 (enzurrona(d)o), 300 (deszorronar), 301, 303((en) zorrón), 305, 400, 401, 500, 501 ((en) zorrón), 502, 600 (enzurrona(d)o), 602, 603; Na 102, 203 (en zorro), 205 ((en) zorrón), 206 (íd.), 301 (íd.), 302 (íd.), 304 (enzorona(d)o), 306 ((en) zorrón), 307 (íd.), 308 (id.), 309 (id.), 400 (id.), 405 (id.), 500 (id.), 501 (id.), 502, 600 ((en) zorrón), 601, 602, 607 (enzorona(d)o); $Z 100$ ((en) zorrón), 101, 200 ((en) zorrón), 202, 300, 301, 302, 304, 400, 401 (enzurrona(d)o), 500, 502, 503, 504, 505, 506, 507, 600 (enzurrona(d)o), 603 (id.); Te 100, 101, 103, 104, 305, 307 (en zurroncito), 308, 402, 404 (y azurrona(d)o), 406; So 400, 600; Gu 400; Bu 400; Vi 300).

$15(H u 603 ; Z 302,304,305,602,603 ;$ Te 200). 
El DRAE recoge esta voz como 'saeta, arma arrojadiza'. Este significado no responde con el sentido del $A L E A N R$. Cabe pensar que se ha producido una metáfora que ha dado un nuevo significado; la agujita del trigo posee la misma forma, o forma similar, a la de una saeta.

Punzón 'lleta' (ALEANR, I, 49). Se encuentra situado en puntos bastante dispersos ${ }^{16}$.

Punzón es un 'instrumento de hierro o de otro material que remata en punta. Sirve para abrir ojetes y para otros usos'. Se ha producido una metáfora, ya que el punzón pincha la tierra para nacer. Como la lleta es pequeña y bastante fina es lógico la utilización de los diminutivos punzonico y punzoncico.

Puga 'lleta' (ALEANR, I, 49).

Se encuentra en cuatro poblaciones de Navarra ${ }^{17}$.

Aunque el DRAE recoge esta voz como un término de poco uso que significa 'púa', debemos señalar que esta forma posee una -g-epentética por lo que nos hallamos ante el término púa. Éste significa 'cuerpo delgado y rígido que acaba en punta aguda' (DRAE). Se habrá dado una metáfora por los rasgos similares entre la agujita del trigo y la púa (la similitud proviene del sentido 'pincha la tierra').

IX. La 'cascarilla del trigo' tiene los siguientes términos metafóricos: casilla, caseta, casquillo, vaso.

Casilla 'cascarilla del trigo' (ALEANR, I, 50). Se encuentra, principalmente, en algunos puntos de occidente ${ }^{18}$.

El DRAE dice que casilla es 'casa o albergue pequeño o aislado, del guarda de un campo, paso a nivel, almenara, puerta del jardín, etc.'.

Se trata de un derivado de casa. Partiendo de este hecho M. Alvar ${ }^{19}$ y Fernández Sevilla ${ }^{20}$ afirman que se trata de un proceso metafórico. El primero sostiene que la metáfora se debe a la idea de refugio o protección; mientras que el segundo opina que «el cambio semántico no resulta difícil de explicar: 'casa pequeña' > 'compartimento de extensión reducida'. Asimismo, puede pensarse en un puente semántico de esta manera: casa 'habitación'- casa 'morada' (del grano del trigo)».

Caseta 'cascarilla del trigo' (ALEANR, I, 50). Aparece en algunas poblaciones de Huesca ${ }^{21}$.

16 (Indicamos los derivados: $H u 301 ; Z 100,402$ (y punzonico), 600 (punzoncico(s)).

$17 \quad(\mathrm{Na} \mathrm{105,106,308,501)}$.

is (Indicamos su derivado casillica: Lo 102, 500, 501,600, 601, 602; Hu 110, 500; Z 501, 502, 504, 505; Te 102 (casillica); So 600; Gu 200; Cs 302).

1) M. Alvar, «Atlas lingüísticos y diccionarios», LEA, IV, 1982, pp. 253-323, pág. 282 ahora en Estudios de Geografia Lingüistica, Paraninfo, Madrid, 1991, pp. 49-115.

$20 \quad$ J. Fernández-Sevilla, Op.cit., pág. 220.

$21 \quad$ (Hu 301, 400, 404, 405, 406, 407, 408). 
EI DRAE afirma que es 'casa pequeña que solo tiene el piso bajo'. A través de una metáfora ha dado 'cascarilla del trigo' pues ésta funciona como si se tratara de la casa del trigo.

Casquillo 'cascarilla del trigo' ( $A L E A N R, \mathrm{I}, 50)$. Forma una área no muy extensa pero compacta ${ }^{22}$.

El DRAE afirma que casquillo es el 'anillo o abrazadera de metal, que sirve para reforzar la extremidad de una pieza de madera'. A partir de la acepción del Diccionario Académico puede deducirse una metáfora (casco 'algo que cubre' $>$ casquillo 'cascarilla del trigo').

Vaso 'cascarilla del trigo' (ALEANR, I, 50). Se localiza en algunos puntos de Logroño, uno de Burgos, Vizcaya y Navarra ${ }^{23}$.

Vaso es 'pieza cóncava de mayor o menor tamaño, capaz de contener alguna cosa' (DRAE). Se ha dado una metáfora por poder ser considerada la cascarilla del trigo como el recipiente que contiene el grano del trigo.

$\mathrm{X} . \mathrm{El}$ 'puñado de mies' recibe las siguientes denominaciones metafóricas: golpe, puño.

Golpe 'puñado de mies' (ALEANR, I, 57). Encontramos este término en dos zonas, más o menos compactas, una de ellas se halla en el noroeste y la otra en el suroeste $\mathrm{e}^{24}$.

Esta forma es una voz de creación metafórica ya que hace referencia a la acción de coger una cantidad de mies en un puñado, haciendo relación al 'golpe', que se da al coger dicha mies.

Puño 'puñado de mies' (ALEANR, I, 57). Se halla en puntos bastante aislados de Logroño, Navarra y Zaragoza ${ }^{25}$.

Puño es 'lo que cabe en la mano cerrada' (DRAE). Para denominar a 'puñado de mies' se ha utilizado puño tras haberse producido una metáfora: la mies que cabe en la mano cerrada es el puño de mies.

XI. La 'llave en la siega' tiene la voz metafórica de llave.

Llave 'llave en la siega' ( $A L E A N R, \mathrm{I}, 38$ ). Encontramos este término en algunas poblaciones de Burgos, Vitoria, Logroño y Huesca ${ }^{26}$.

22 (Inidicamos las variantes fonéticas casquijo, cascajo, cascullo, cuando no indicamos nada se trata de casquillo: Lo 103 (casquijo), 301 (id.), 305 (id.), 603 (id.), 604 (id.); Na 106 (id.), 205 (id.), 303 (id.), 304 (id.), 307 (id.), 400 (id.); Te 201 (cascullo), 203, 300 (cascullo), 305 (casquijo), 400 (cascullo), 401, 402 (casquijo), 403 (cascajo, 404 (id.), 503 (casquijo), 600 (id.)).

23. (Lo 100, 101, 300, 401; Na 306; Bu 400; Vi 300).

$24 \quad($ Lo $102,103,300,301,302,303,304,305,401,500,501,502,600,601,603,604 ; \mathrm{Na}$ 104, 106, 200, 304, 306, 307, 308, 500, 501, 602; Hu 106, 301, 303,601; Z 504, 505, 506; Te 101, $103,104,301,302,303,304,305,306,308,402,406,502,600 ;$ Gu 200, 400; V 100, 101; Cs 301, 302; So 402; Bu 400; Vi 600).
25
(Lo I00; Na I03, 105, 301, 303; Z 301, 305).
$26 \quad($ Bu 400; Vi 300, 600; Lo 102, 500, 501; Hu 204). 
El DRAE asegura que llave es 'cuña que asegura la unión de dos piezas de madera o de hierro, encajada entre ellas'. La metáfora viene dada por la función que tiene la llave en la siega, es decir, llave es 'Io que sirve para cerrar'.

XIII. 'Vaciarse el haz sin que se rompa el vencejo' recibe las siguientes voces metafóricas: (d)esbotifarrar(se), desbarrigarse.

(D)esbotifarrar(se) 'vaciarse un haz sin que se rompa el vencejo' (ALEANR, $I, 65)$. Se encuentra en algunas localidades del sur de Teruel, así como en una zona de Zaragoza ${ }^{27}$.

(D) esbotifarrar es un derivado de botifarra palabra catalana que significa 'morcilla'. Una morcilla es un 'trozo de tripa de cerdo, carnero o vaca, o materia análoga, rellena de sangre cocida, que se condimenta con especias y, frecuentemente, cebolla, y a la que suelen añadírsele otros ingredientes como arroz, piñones, miga de pan, etc.' (DRAE). Cuando a una botifarra se le sale el interior se dice que se ha desbotifarrado. De ahí se ha producido una metáfora.

Desbarrigarse 'vaciarse un haz sin que se rompa el vencejo' (ALEANR, I, 65). Se encuentra en tres localidades de Zaragoza, dos de Navarra y uno de Logroño ${ }^{28}$.

De barriga se forma desbarrigar. El DRAE afirma que desbarrigar es 'romper o herir el vientre o barriga'. Se ha producido una metáfora desde el sentido de romper que apunta el Diccionario de la Academia, pues cuando el haz se vacía, éste se desbarriga 'le salen las tripas al haz', independientemente de que se rompa o no se rompa el vencejo.

\section{Conclusiones}

Muchos términos van adquiriendo nuevas acepciones porque en ellos se han producido metáforas, deslizamientos semánticos, metonimias, restricciones semánticas, etc., otros sentidos, sin embargo, caen en el olvido ya que dejan de usarse. Este movimiento, como ya hemos indicado en líneas anteriores, no aparece reflejado en el diccionario porque éste «fosiliza a las palabras, les da un nicho en el que quedan inmovilizadas y en el que se perpetúan de generación en generación ${ }^{29}$. Sin embargo, en los atlas lingüísticos podemos observar todos estos cambios porque en ellos «cada palabra no se desgaja de un ambiente en el que vive, con el que se enlaza y del que adquiere los jugos que le dan la vida» ${ }^{30}$.

27 (Indicamos entre paréntesis sus variantes fonéticas por ser éstas las más utilizadas: $Z 607$ (ezbotiferrase); Te 305 (ezbotifase), 308 (ezbotifarrase), 403 (ezbotifarrace), 405 (se ezbotifarra), 504 (ezbotifarrarse)).

28 (Indicamos sus variantes: $Z 500$ (ezbarriga(d)o), 501 (ezbatigase), 503 (se ha ezbarriga(d)o); Na 301, 304; Lo 604).

29 M. Alvar, «Atlas lingüísticos y diccionarios», pág. 274.

30) Ibiden, pág. 274. 
En nuestro trabajo hemos señalado numerosos términos que han adquirido nuevos significados a través de metáforas. Muchas de estas voces aparecen recogidas en el Diccionario Académico aunque no con el sentido que poseen en el ALEANR a pesar de que en muchos casos su extensión es considerable:

cabellera 'barba de la mazorca' ( $A L E A N R, I, 107)$; seda 'barba de la mazorca' (ALEANR, I, 107); cabeza 'mazorca' (ALEANR, I, 109); escoba 'flor del maíz' (ALEANR, I, 106); cabeza 'flor del maíz' (ALEANR, I, 106); capota 'farfolla' (ALEANR, I, 108); corazón 'carozo' (ALEANR, I, 111); troncho 'carozo' (ALEANR, I, 111); espalocar 'desfarfollar' (ALEANR, I, 110); flecha 'lleta' (ALEANR, I, 49); punzón 'lleta' (ALEANR, I, 49); puga 'lleta' (ALEANR, I, 49); casilla 'cascarilla del trigo' (ALEANR, I, 50); casquillo 'cascarilla del trigo' (ALEANR, I, 50); vaso 'cascarilla del trigo' (ALEANR, I, 50); caseta 'cascarilla del trigo' (ALEANR, I, 50); golpe 'puñado de mies' (ALEANR, I, 57); puño 'puñado de mies' (ALEANR, I, 57); llave 'llave en la siega' (ALEANR, I, 38 ); desbarrigarse 'vaciarse un haz sin que se rompa el vencejo' (ALEANR, I, 65).

Al inicio de este trabajo señalábamos que una metáfora se establece a partir de la comparación tácita de dos términos. Así pues encontramos metáforas que se han formado partiendo de las características comunes entre las dos voces, por la situación que ocupan ambos términos, por poseer funciones similares, etc.:

Por la situación: cabeza 'mazorca' (ALEANR, I, 109); cabeza 'flor del maíz' (ALEANR, I, 106); corazón 'carozo' (ALEANR, I, 111).

Por poseer características o funciones similares: troncho 'carozo' (ALEANR, I, 111); flecha 'lleta' (ALEANR, I, 49); punzón 'lleta' (ALEANR, I, 49); puga 'lleta' (ALEANR, I, 49); anillada 'llave' (ALEANR, I, 38).

Por la idea de refugio o protección: casilla 'cascarilla del trigo' (ALEANR, I, 50); caseta 'cascarilla del trigo' (ALEANR, I, 50).

Si la lexicografía tuviera presente los datos que le proporciona la geografía lingüística podría mejorar considerablemente tanto la macro como la microestructura de los diccionarios. De este modo nuestros diccionarios serían obras, más o menos, actualizadas.

\section{Bibliografía}

ALCOVER, A.M., y F. DE B. MOLL, Diccionari català, valencià, balear, Moll, Palma de Mallorca, 1979, 10 v.

ALVAR, M., Atlas lingüísticos y diccionarios», LEA, IV, 1982, pp. 253-323; ahora en Estudios de Geografía Lingüística, Paraninfo, Madrid, 1991, pp. 49-115.

ALVAR, M., LLORENTE, A., BUESA, T., Y ALVAR E., Atlas Lingüístico Etnográfico de Aragón, Navarra y Rioja, Departamento de Geografía Lin- 
güística, Instituto Fernando el Católico de la Excma. Diputación de Zaragoza, CSIC, Zaragoza, 1979-1983, 12 tomos.

ANDOLZ, R., Diccionario aragonés, Librería General, Zaragoza, 1977.

BORAO, G., Diccionario de voces aragonesas, Imprenta y Librería de don Calisto Ariño, Zaragoza, 1859.

COROMINAS, J., Diccionari etimològic i complementeri de la llengua catalana, Curial, edicions catalanes, Barcelona, 1983-1991, Madrid, 1976, 8 v.

COROMINAS, J., J.A. Pascual, Diccionario crítico etimológico castellano e hispánico, Gredos, Madrid, 1980-1991,6v.

EGUÍLAZ Y YANGUAS, L., Glosario etimológico de las palabras españolas (castellanas, catalanas, gallegas, mallorquinas, portuguesas, valencianas y bascongadas) de origen oriental (árabe, hebreo, malayo, persa y turco), Atlas, Madrid, 1974, (1 $1^{\mathbf{a}}$ edic. 1886).

FERNÁNDEZ SEVILLA, J., Formas y estructuras en el léxico agrícola andaluz (Interpretación y estudio de 200 mapas lingüísticos), CSIC, Departamento de Geografía Lingüística y Dialectología, Madrid, 1975.

GARCÍA DE DIEGO, V., Diccionario etimológico español e hispánico, Sacta, Madrid, 1954.

GARCÍA SORIANO, J., Vocabulario del dialecto murciano, Editorial Regional, Murcia, 1980, edición facsímil de la primera, Madrid, 1932.

GOICOECHEA, C., Vocabulario riojano, Anejo VI del DRAE, Madrid, 1961. IRIBARREN, J.M., Vocabulario navarro seguido de una colección de refranes, adagios, dichos, frases proverbiales, Diputación de Navarra, Institución «Príncipe de Viana», Pamplona, 1952.

NAVARRO CARRASCO, A.I., «Geografía Lingüística y diccionarios», ELUA, 9 (1993), págs. 73-96.

NAVARRO CARRASCO, A. I., «Voces de creación metafórica en el $A L E A$ », LEA, X/1 (1988), págs. 107-114.

REAL ACADEMIA ESPAÑOLA, Diccionario de la lengua española, EspasaCalpe, Madrid, 1992. 